\title{
Cyberpark, a New Medium of Human Associations, a Component of Urban Resilience
}

\author{
Konstantinos Lalenis $^{1(\bowtie)}$, Balkiz Yapicioglou ${ }^{2}$, \\ and Petja Ivanova-Radovanova ${ }^{3}$ \\ ${ }^{1}$ DPRD, University of Thessaly, Volos, Greece \\ klalenis@prd.uth.gr \\ 2 Arkin University of Creative Arts and Design, Kyrenia, Cyprus \\ kaylabalkiz@yahoo.com \\ 3 Association for Integrated Development and Sustainability, Sofia, Bulgaria \\ petjaivanova@gmail.com
}

\begin{abstract}
The centre point of this chapter is how to increase the resilience of the urban environment by integrating the cyberpark in its spatial planning and policies. Disaster prevention and preparedness are a priority in resilience, and two major related sectors are infrastructure and information. Significant components of prevention infrastructure in cities are public/free spaces. Public spaces are used as refuge in cases of natural disasters (earthquakes, fires etc.), but also as spaces of physical contact, communication, community bonding, and provision of social services in cases of social crises (the cases of refugees). Information, as the other major sector of prevention, may vary from dissemination of information in an individual basis, to information exchange in a collective basis, the latter being of significant value in cases of prevention. The collective basis of information exchange is further expanded and technologically improved through Information and Communication Technologies (ICTs). This chapter focuses on the psychological and social roles of 'the cyberpark' in extraordinary events and illustrate the importance of its physical form and spatiality. Cyberparks combines and explores the relationship between Information and Communication Technologies (ICTs) and urban open/public spaces. In this sense, they combine elements of both, prevention infrastructure and information, and they constitute significant components of urban resilience.
\end{abstract}

Keywords: Urban resilience - Disaster prevention in planning •

Planning for resilience $\cdot$ Social inclusion of refugees $\cdot$ Refugees and cyberparks

\section{Introduction}

The aim of this chapter is to discuss the necessity of cyberparks, as defined and developed by the COST TU1306, as redundant infrastructure in maintaining resilience of urban environment in times of crises. Resilience, for the purpose of this chapter, is the capacity of a system to cope with disturbances and safeguard overall system persistence. Disturbances are associated with disruption of the functioning of a community 
due to events of natural, geophysical, technological, social, or human behavioural nature. Disaster prevention and preparedness is, thus, a priority, and can take the form of development of rapid response capacities, or of prevention through the formulation of a longer-range strategies and policies. Essential elements for disaster prevention and preparedness are infrastructure and information.

Public open spaces (POS) are significant components of both, prevention infrastructure and locations of information exchange and management. Being part of the urban fabric, besides their function as catalysts in the improvement of quality of life of city dwellers, they are also used as refuge spaces for local population in the event of disasters (earthquakes, fires, etc.). In such cases, as well as in cases of social or human behaviour events, they also function as spaces of physical contact, communication, community bonding, and provision of social services. The case of refugees gathering in POS, are indicative of the above. Information may vary from dissemination to exchange, on individual or collective basis, and it is further expanded and technologically improved through Information and Communication Technologies (ICTs).

In cyberparks, on the other hand, "POS characteristics and cyber technologies blend together to generate hybrid experiences and enhance quality of life" (Smaniotto Costa and Ioannidis 2017). ICT can be used in this context to give or gather information, to aid co-creation of space, to allow crowd sourcing of information and opinions, and to allow affective sharing or self-monitoring of activities. As such, they combine and explore the relationship between ICTs and urban open/public spaces. In this sense, they combine elements of both, prevention infrastructure and information and they constitute significant components of urban resilience. We presume cyberparks are able to support urban resilience faster and in a more efficient way than traditional POS.

The COST TU1306 mainly explores the relationship between ICT and POS and how this relationship can contribute, provide opportunities and support transforming cities into more social and inclusive environments. The above definition of cyberparks implies but does not adequately emphasize the resilience dimension of such urban landscapes. In fact, cyberparks might be also seen as places purposely used in cases of disturbances and disruption of the functioning of a community due to events of varying nature. Thus, the attempt of this chapter is to contribute to the definition of a role of ICT in planning and maintenance of the contemporary public open space in regard to risk prevention and maintaining resilience in the urban environment.

\section{Concepts, Definitions, and Relationships}

\subsection{Research Concept and Methodology}

Cyberparks combine and explore the relationship between ICTs and urban open/public spaces. In this sense, they combine elements of both, prevention infrastructure and information and they constitute significant components of urban resilience. However, firstly, there is a need to integrate the two meanings of resilience, that is, the short-term capacity of the 'Host City' to absorb the crisis of the sudden event by providing immediate safety and avoid panic by information and guidance, and the long-term capacity of the 'Host City' to develop structures facing this crisis by integrating 
cyberparks into spatial planning and related spatial policies. Illustrations of the above will be given by further analysis in case studies, covering aspects of cyberparks that increase urban resilience to physical disasters, as well as to disasters due to human behaviour (refugees). The latter will be given special emphasis, since it is a very recent, massive, unexplored, and with enormous humanitarian consequences phenomenon.

In analysing the potential of cyberparks to increase urban resilience to physical disasters the research will focus on particular sectors of Master Plans, where official guidelines prescribe the conditions and urban infrastructure for prevention and protection of natural disasters (earthquakes, fires, floods, etc.). (Ministerial Decision 9572/1845, FEK 209/7-4-2000). In the guidelines special emphasis is given to the uninhibited access to POS from the local population, and to the infrastructure of POS, which should facilitate information exchange between the responsible authorities and the population gathered in POS. The analysis will provide evidence for the adequacy of cyberparks to cover the above needs, and proceed a step further, in facilitating communication and contact between individuals, families, and groups of people in times of massive panic, and uncontrolled emotional reactions.

Cyberparks that increase urban resilience to human behaviour disturbances and disasters will be analysed within the frame of the refugee crisis, which "front line" European cities are forced to sustain. The need of refugees to gather in POS for contact and communication, and their -almost absolute- reliance in smartphones for information exchange with authorities, NGOs, friends, and family, are documented from various sources, these being articles in newspapers, the Internet, scientific publications, and related TV reporting. Verification for the above will also be sought from interviews taken in the course of research undergoing in the DPRD of the University of Thessaly (Pyrpiri 2017). The degree that the refugees cover basic, everyday needs by the above means indicates the state of resilience of the particular city, town, or neighbourhood. The appropriation of POS by the refugees, and their use of ICT for information exchange, proves the necessity of cyberparks for maintaining resilience in these cases, and even more since cyberparks can combine POS and ICT in the same place, at the same time.

Finally, the necessity of cyberparks as redundant infrastructure in maintaining resilience of urban environment will also be shown by investigating the "fitness" of cyberparks for accommodating the resilience indicators used in the Circle of 100 Resilient Cities, and more specifically, in its implementation in particular resilience studies.

\subsection{Defining Urban Resilience}

In the literature, the notion of resilience has been explained with reference to different perspectives from different fields and has attained multiple levels of meaning. However, even though resilience is defined differently according to these different research domains, a common factor underlying each definition is the notion of disturbance and adaptation in the context of a system, or, the ability or capacity to deal with disturbance. These disturbances might originate from variety of disasters and stresses (human made or natural) and might possess slightly different meanings, however, what they really point is some sort of internal or external change. 
Resilience is not a new concept. However, it has evolved through its application in different disciplines with the majority of the work on resilience adapting the concept of ecological resilience. Within the notion of smart cities, for example, there is a shift in risk management on the city level in the sense that "resilient cities" are not in opposition to ecological modernisation, but rather a refinement. (Androbus 2011). In ecology, resilience is related to 'the ability to adapt to a change' (Holling 1973; Walker et al. 1981; Folke 2006), 'the capacity of a system to absorb disturbance' (Walker et al. 2004; Walker and Salt 2006), or "the capacity to change in order to maintain the same identity" (Folke et al. 2010). The theory of resilience has been influenced by general systems theory and complex adaptive systems (CAS), where a system is defined as complex interaction and relationships between different agents/elements, and can be anything that functions (Bertalanffy 1968; Holling 1973). This theory also posits that the relationships between the agents of the system are more important than the agents themselves. Resilience is also affiliated with other combinations of relationships, such as vulnerability, persistence, change and transformations.

The concept of resilience in urban studies has also evolved from the concept of ecological resilience where 'urban resilience' can be viewed as having the concept of resilience applied to that of cities. Using the perspective of ecological resilience, therefore, urban resilience is usually described as "the ability of a city or urban system to withstand a wide array of shocks and stresses". However, urban resilience is not only about surviving potential risks and threats and recovery, but rather about grasping the positive outcomes these changes and transformations might bring. Moreover, urban resilience requires us to think in an integrated way and should incorporate other important societal aspects. Like Folke et al. (2010) emphasize, a social perspective, especially regarding social change, is an essential part of resilience. We should also acknowledge the fact that creating resilient cities requires 'resilient thinking' to adapt to the outcome of change.

Urban spaces, from infrastructure to open spaces, are vital agents of the urban system and strengthened adaptable spaces can contribute to resiliency of a city. As a matter of fact, increased 'resilient thinking' is initiating urban adaptation planning within cities to update important physical and societal systems. As Montgomery (1998) posits, adaptable urban space can "accommodate complex patterns of diversity, mixture and economic grain".

\subsection{Infrastructure and Information as Major Sectors of Disaster Prevention and Management. Public/Free Spaces as Important Component and Common Ground of Infrastructure and Information}

Cities and infrastructure have always co-existed where their relation has been interdependent and co-evolutionary. Furthermore, along with social, political, administrative, and economic forces, the transformation of social space in general and urban space in particular is credited to the transformative power of infrastructure. As a matter of fact, cities owe their position on the global stage to the networking of the infrastructures, which have re-organized relations among peoples, institutions, and places (Neuman and Smith 2010). 
The meaning of infrastructure has expanded over the years, whereas traditional meaning of infrastructure conjures up the notion of built facilities and networks made by humans for public consumption either above or below ground. Another important definition of infrastructure is that, as explained by Frischmann (2012), infrastructure is a 'resource' that should be "accessed and used concurrently by multiple users for multiple uses". This explanation combined with the traditional explanation of infrastructure then leads to categorize infrastructure as 'essential'. Essential resources are indispensable for survival; however, they are context specific and go beyond access to basic needs. Moreover, infrastructure resources conjure up the notion of a shared community resource claiming the identity of "commons" which take on a utilitarian character as open and accessible to life sustaining resources. Commons as a resource, on the other hand, include public spaces such as parks, streets, sidewalks and plazas and even extends to spaces where access by public is limited and regulated like schools, libraries, courthouses and even privately-owned shopping malls. Considering the above-mentioned combined definition of infrastructure as resources and commons then summons public spaces as essential elements of urban infrastructure.

Even though, the public spaces' spatial impact and transformative power that shape complex systems of human activity is well perceived "it does not receive the appreciation it deserves since its continuous availability is assumed and is just part of the background...however, the importance emerges when the disaster strikes" (Frischmann 2012). The essentiality of the infrastructures, herein the public spaces, should not only be considered for 'good' times, but 'bad' times as well. Cities are full of uncertainty and also face major disasters, shocks and disturbances (i.e. human crises, climate change or simply rapid demographic change). The pressure on public spaces increases during such events, especially with traumatic events like war, destruction and devastation with increased interest in public spaces. When we visit our recent history, we can observe this pressure from how public spaces are transformed into refuge spaces (from evacuation camps to places that serve basic human needs like temporary shelters) for disaster management to reduce vulnerability of cities, therefore contributors to city resilience (e.g., during the 2006 Lebanon war, Sanayeh Garden in Beirut acted as refugee camp for 450 people who lost their homes for months).

Considering importance of the public space during 'bad' times as a place of refuge, the connectivity to the rest of the world for exchange of information becomes another essentiality. When we define public spaces as essential urban infrastructure, therefore, we also have to take into account the deployment of information (ICT) in public spaces and their essentiality, and how ICT promotes efficiencies and functionalities in public spaces during crisis. As a matter of fact, public spaces are conceptualised as an opportunity for the exchange of messages with diverse others (Lofland 1985) and it is only natural that today cities incorporate ICT into planning of public spaces for creating more social and inclusive environments, not only for 'good' times but also for 'bad' times. In other words, public spaces as an infrastructure resources should be considered as spare capacity embedded in the city, or as a redundancy, which is one of the most important factors contributing for city resilience. As a matter of fact, according to 100RC (100 Resilient City) resilient cities demonstrate seven qualities; reflectiveness, resourcefulness, robustness, redundancy, flexibility, inclusiveness and integration. 


\subsection{Cyberparks as Significant Components of Urban Resilience. The Effective Combination of Infrastructure and Information in Cyberparks, for Disaster Prevention and Management}

ICT (information), along with infrastructure, is another force that possesses the power to transformation in cities, or spatial impact. The power of information and its transformative power of public space is not a new concept (Hampton et al. 2015) but how this power can contribute to urban adaptation planning approaches for resilience is an area that needs attention. As Montgomery (1998) emphasizes, "the successful urban area-in this case public spaces- is one which offers in-built adaptability rather than in-built obsolescence". Increased resilient thinking is making urban planners within cities to update important physical and societal systems. Resilient thinking in urban adaptation planning requires new approaches to manage resources. With resilient thinking, however, we cannot expect to tailor a 'one size fits all' approach to city resilience because of the locality of the matter and different adaptability difficulties each city faces. The challenges of adaptation planning are quite diverse, nevertheless, the top three adaptation challenges identified are "(1) securing funding for adaptation; (2) communicating the need for adaptation to elected officials and local departments; and (3) gaining commitment and generating appreciation from national government for the realities of local adaptation challenges" (Carmin, Nadkarni and Rhie 2012). Considering the abovementioned urban planning adaptation challenges, therefore, it is important we clearly communicate the multi-dimensional benefit of public space adaptation.

As per the objectives of COST TU1306, cyberparks are proposed as spaces with a power to transform cities into more social and inclusive environments (rather than just being parks equipped with high technology) and as spaces offering additional opportunities to people using these spaces. As a matter of fact, these objectives with the different approaches to manage urban resources suggested by resilient thinking lead this research to explore some other spill-over effects of cyberparks in cities specifically during a crisis.

When we look into the definition of resilience, especially city resilience, one of the most important components of resilience, is access to resources. Cyberparks, as public spaces, can be considered as a new resource within the urban adaptation planning where infrastructure and information are combined. Cyberparks may add different functions to public spaces (spill-overs as additional opportunities), which might also contribute as a redundant and flexible resource to city resilience in time of crisis. Therefore, respecting the objectives of the COST TU1306 project, public spaces incorporated with ICT, simply cyberparks, are proposed as part of city infrastructure resources and spaces of refuge for the people on the move (specifically for the refugees in receiving countries) contributing for city resilience. However, before we discuss how cyberpark can contribute to city resilience as a place of refuge, it is also critical that we further define the boundaries of public space within the context of this chapter. Therefore, for the purpose of this study, public spaces (cyberparks) will be defined as information landscapes, a new infrastructure resource, to which all members of public in a society have legal access, including people on the move, i.e. refugees, with no limitation and regulation. After all, as Carpenter et al. (2001) states we need to establish "of what, to what, and under what conditions" when considering resilience in a system. 


\section{Cases Studies}

\subsection{Cyberparks Increasing Urban Resilience to Physical Disasters. Provisions in Spatial Planning}

Urban resilience, recently, has been an important element in planning, and has been included in Master Plans, Strategic Plans, and related sectoral studies of cities around the world. In most of these studies, public open spaces (POS), have been recognized as significant factors in almost all forms of urban resilience. In cases of natural hazards (earthquakes, fires), in particular, POS were treated in Master Plans as crucial elements of the city preparedness to reduce the magnitude of disasters, even before urban resilience was elaborated as a notion. They were organized as first stage refuge spaces, where local population should be gathered in order to escape from being trapped in buildings, to get first aid, water, food, temporary shelter, and try to get informed about friends and relatives. In these plans, prime emphasis was given to safeguarding safety and providing first aid. With the development and inclusion of urban resilience in planning, other forms of resilience were also examined, and disaster prevention and management were enriched with more elements than safety and first aid. Information and communication were quite important among them, which, if incorporated in POS, they are adequately covered by the definition of cyberparks, as provided by COST TU1306.

Cases from Germany and Greece illustrate how cyberparks may increase urban resilience to physical disasters. They are derived from families of nations in spatial planning with diverse traditions and practices, considered as occupying the two opposite ends in the spectrum of planning policies (ESPON 2.3.2): from the Comprehensive Integrated and the Regional Economic (Germany) and from the 'urbanism' tradition (Greece). In Germany, the cities of Bonn and Duisburg have been assessed in resilience concerning low carbon activities (Lindner et al. 2014:16). The importance of incorporating cyber technology in their green and open spaces is highlighted, mainly for raising public awareness in renewable energies through activities organized in POS, including the exhibition of a GIS heat map, where the information of a solar cadastre and the existing energy supply will be integrated, as a basis for strategic decisions. In Greece, on the other hand, the notion of resilience became apparent in most recent Master Plans, after 2010. The Masterplan of the city of Xanthi (47000 population, expected to be approved by the end of 2017), has a separate chapter concerning disasters and social crises. It was based on a sectoral plan, been provided by a national plan coded Xenocratis (2003), but besides referring and mapping the POS to be used as refuges of the affected population in earthquakes, floods, and fires, there was also specific focus on climate change and social crises (massive arrival of refugees). In that, special emphasis was given to the appropriate infrastructure of the above-mentioned POS, which would facilitate the multi-dimensional flow of information among the affected population and public and administrative bodies involved. It also prescribed for a special study of immediate priority, related to the resilience of the city.

The above examples illustrate the inclusion of the notion of urban resilience in European spatial planning, while giving special emphasis in importance of the role that POS equipped with ICT (i.e. cyberparks) may have for safeguarding and reinforcing resilience. 


\subsection{Cyberparks Increasing Urban Resilience to Disasters Due to Human Behaviour (Refugee Crisis in Europe)}

The significance of cyberparks as a means for safeguarding and reinforcing urban resilience can also be exhibited in the case of social crises. The recent refugee crisis is on the forefront of international development, when the combination of natural disasters, and armed conflict have displaced millions of people in Europe and worldwide. Cyberparks are proposed as part of city infrastructure resources and spaces of refuge for the people on the move (specifically for the refugees in receiving countries) contributing for city resilience. Analysis of the relationships between a. refugees and POS, and $b$. refugees and information technology will test the validity of the above proposal. The interface between these two relationships is the relation between refugees and cyberparks and might be considered as a measure for urban resilience.

\section{The Relationship Between Refugees and POS}

Refugees arrive in high numbers, fighting with the waves of the Mediterranean Sea, in the Aegean islands and in the south of Italy. During their perilous journey, and upon their arrival in Europe, the needs for information and communication are of fundamental value to them. At the same time, various elements of their lives lose in individuality and become by need, increasingly collective. Accordingly, their needs and uses of space are transformed from individual to collective.

POS were usually among the first spaces to provide accommodation at the first waves of refugee arrivals, and some of them were since transformed in semi-permanent reception camps. Here, the phenomenon of appropriation of space appeared to take interesting dimensions, which, in turn, triggered rearrangements in the urban form, and readjusted social relations with the local communities. Examples in the main squares of Omonoia and Victoria in Athens (Greece), and Lavov Most and Maria Louiza Boulevard in Sofia (Bulgaria) are indicative examples of the above. The reverse phenomenon was later observed in the more organized reception camps, where new POS were co-created by refugees and the various social agents involved in the life in the camp.

The main needs of the refugees to use and often appropriate POS was analysed in various studies, and can be summarized in the following way: getting together, learning about family and friends, seeking to organize their lives in the immediate and midterm future, exchanging information, making new friends, and learning about their new environment and how they are expected to function in it. POS can be places that include rather than exclude. Refugees are not tucked away in a hall or community centre, but a visible and engaged presence within the diverse mix of local residents. ("Refugees welcome in parks" project, Sheffield University 2017).

However, there are challenges. The public realm can be a place where refugees feel uncertain about local norms, feel unwelcome, uncomfortable or are vulnerable to hate crime. Longstanding residents of a local area may react negatively to changing patterns of use of public spaces, especially when 'hanging out' is perceived as idle loitering, threatening, or fundamentally changing the ethos of a loved place. An increase in 
hostile architecture and management practice (implicitly acting against street sleeping) also impacts on combine and explore. («Refugees welcome in parks» project, Sheffield University 2017). In a series of face-to-face interviews of owners and/or shop-keepers of restaurants and coffee places in Lavov Most area in Sofia, carried out by IvanovaRadovanova for the purpose of this chapter, it was found that the main concerns of the local shopkeepers were about security and safety issues, they attributed the causes of social disturbances to the massive arrivals of refugees, and they were asking for more police surveillance.

\section{The Relationship Between Refugees and Information Technology}

It has been observed that refugees very frequently carry smartphones, of quite advanced technology (Lloyd (2015:2). In fact, according to Middle East Online (19-82015), many migrants consider their smartphones to be more important than food. As Gillespie et al. (2016:2) state "For refugees seeking to reach Europe, the digital infrastructure is as important as the physical infrastructures of roads, railways, sea crossings and the borders controlling the free movement of people". Current research and activities on refugee's use of mobile technology focus largely on the following themes: connectivity, digital tools and platforms, family reconnection, education, and livelihoods and mobile money. In the above, one has to add that smartphones are also a means to document the tragedy through which these people have been through.

The multiple usage of smartphones by the refugees has been documented by many writers (Chib and Aricat 2016; Talhouk et al. 2016; Harney 2013, etc.). Gifford and Wilding (2013) argue that if refugees are able to maintain their connections to family and friends, which can be achieved through a variety of mobile-based apps and Social Media applications, they may experience a greater sense of "being at home" in a hosting country. Finally, the role of ICT in promoting social inclusion has been analyzed by AbuJarour and Krasnova (2017) in their research about Syrian refugees in Germany. In their analysis, they construct a context framework for refugees (home country, journey, hosting country) within which ICTs function. Three variables of this function are derived (ICT properties, capabilities enabled by ICT, and achievements in social inclusion) inter-influenced by indicators (immigration, family separation, new society, and also internet, smartphones, and social media).

Besides the above, though, the use of smartphones on a mostly individual basis suffers from significant disadvantages and shortcomings (Gillespie et al. 2016). Technical problems included frauds in buying SIM cards which did not provide the desired international communication, shortage of installations for charging batteries, instability of connections, Wi-Fi access not often available, affordability of SIM cards, profiteering of locals by selling phone charging services in extremely high prices, and/or information gap because of language barriers. Other problems are mostly related to gendered and generational differences in access and use, poverty, illiteracy, and inadequacies in provision of services such as education, physical and psychological health etc. Schmitt et al. (2016) detected and defined a «digital divide» among refugees in the Za'atari Syrian refugee camp in northern Jordan, creating, thus, social divisions 
among the refugees. In this way, the class structure of society was transformed in the refugee camps/communities in another class division, based on access and possession of means of connectivity and information. This social divide becomes highly striking considering that contrary to Syrians, Afghans and some Iraqis appear to be less well equipped with ICT. Furthermore, the divide gets deeper as it concerns specific subdivisions of the above groups. UNHCR found that women, the elderly, less educated and/or illiterate people are less likely to have access to technology, information, and devices, echoing the findings of other, non-refugee related studies of exclusion, such as GSMA's Connected Women (GSMA 2016).

\section{Conclusions}

This contribution has explored the inclusion of the notion of urban resilience in European spatial planning, while giving special emphasis to the role that POS equipped with ICT (i.e. cyberparks) may have for safeguarding and reinforcing resilience. Having also exhibited the strong relationships between a. refugees and POS, and b. refugees and information technology - mainly smartphones - and the accruing problems and shortcomings, we conclude with an equivalent relationship between refugees and cyberparks that can alleviate the above shortcomings and thus strengthen urban resilience.

ICT in cyberparks is not restricted to smartphones, but it includes multiple technologically advanced means for achieving the above objectives. Furthermore, they allow and encourage collective consumption and use of ICT, strengthening, thus, the internal bonds of the users as a social group. The organized provision of information and the multiple ICT tools in cyberpark infrastructures can tackle the technical problems incurred to refugees with smartphones, by guaranteeing usable means for desired international communication, availability and affordability of installations for charging batteries, stable and unlimited Wi-Fi access, affordability of SIM cards, and assistance in overcoming language barriers.

With education and language skills seen as being vital to successful integration and social inclusion, a shortage of teachers in refugee hosting places complicates current efforts towards this objective. Here, online modes of pedagogy can potentially fill the gap (AbuJarour and Krasnova 2017). It is argued, that this type of education is unlikely to be as effective as in-person education, and such education services towards social inclusion require particular infrastructures and process. Cyberparks may be equipped by this type of infrastructure and provide a collective environment for open air activities of educational nature for children and adults. This has been shown to be more productive than the equivalent isolated use of smartphones by individuals. In a similar collective vein, help for sometimes illiterate refugees could be offered by the use of video or sound resources. Important initiatives could be the provision of legal advice and information about language learning facilities in info kiosks, or similar information installations. These are key areas that cyberparks could focus on.

Finally, a means of social inclusion of great importance is supporting refugees in combining virtual and local communication. In cyberparks, it is feasible and desirable to bring both refugees and locals together to support the integration process. The need 
to feel connected to other people is one of the primary psychological concerns of refugees, while the stresses upon them can often lead to isolation. The design process of POS equipped with cyber technology can facilitate communal connections. Including local people and refugees in the design process and looking at desired ICT and other services, cyberparks can become more relevant to the populations that live there. ("Refugees welcome in parks" project 2017). A number of co-operative methods for understanding public needs, civic involvement in the development of urban policies, spatial planning, and design are essential. The improvement of urban resilience and quality of life requires participation of both, local population and refugees, their collaboration and citizen involvement, aiming at a shift in the relative power of actors involved. Common cultural activities with concurrent events transmitted from refugees homelands, games between groups located in different areas and brought together by ICT means, interaction in the common language of cyber matters between local and refugee youths, watching sports, concerts, and cultural and political events through big screens, ("Refugees welcome in parks" project 2017), and discussing and sharing experiences and knowledge from distant places through ICT, strengthen the community bonds between locals and the newcomers, and accelerate social inclusion.

BBC Media Action's Voices of Refugees project also finds a close relationship between resilience and the psychosocial capacity of refugees and their use of ICT. "The analysis showed that participants who stayed in regular contact with other refugees and who had wide communication networks were likely to be more resilient and feel less vulnerable than those who were not connected." (Bailey et al. 2016). Undoubtedly, there is a recognized need to keep POS as a neutral space for practice and learning. Further institutionalization and the development of cyberparks will support improvement of accessibility of information, and empowerment of different stakeholders, including refugees for spatial and social organization on both local level and city levels. In order to overcome problematic encounters between planning and society, the incorporation of a kind of self-organization in planning with support of ICTs might be a successful next step. If cyberparks, as shown above, can retain this psychological capacity and further enhance it by the provision of infrastructure of a more collective nature, and of a more global use of ICT technology, which surpasses individual phones, then cyberparks can safeguard and reinforce urban resilience in times of social crises.

\section{References}

AbuJarour, S., Krasnova, H.: Understanding the role of ICTS in promoting social inclusion: the case of syrian refugees in Germany. In: Twenty-Fifth European Conference on Information Systems (ECIS), Guimarães, Portugal, pp. 1790-1806 (2017)

Androbus, D.: Smart green cities: from modernization to resilience? Urban Res. Pract. 4(2), 207$214(2011)$

Bailey, N., Hannides, T., Kaoukji, D.: Voices of refugees; information and communication needs of refugees in Greece and Germany. BBC Media Action (2016). https://downloads.bbc.co.uk/ mediaaction/pdf/research/voices-of-refugees-research-report.pdf

Bertalanffy, L.V.: General systems theory: foundations, development, applications. New York (1968) 
Carmin, J., Nadkarni, N., Rhie, C.: Progress and Challenges in Urban Climate Adaptation Planning: Results of a Global Survey. MIT, Cambridge (2012)

Carpenter, S., Walker, B., Anderies, J.M., Abel, N.: From metaphor to measurement: resilience of what to what? Ecosystems 4(8), 765-781 (2001)

Chib, A., Aricat, R.G.: Belonging and communicating in a bounded cosmopolitanism: the role of mobile phones in the integration of transnational migrants in Singapore. Inf. Commun. Soc. 20(3), 482-496 (2017)

Frischmann, B.M.: Infrastructure: The Social Value of Shared Resources. Oxford University Press, Oxford (2012)

Folke, C.: Resilience: The emergence of a perspective for social-ecological systems analyses. Glob. Environ. Change 16, 253-267 (2006)

Gifford, S.M., Wilding, R.: Digital escapes? ICTs, settlement and belonging among Karen youth in Melbourne, Australia. J. Refug. Stud. 26(4), 558-575 (2013)

Gillespie, M., et al.: Mapping Refugee Media Journeys Smartphones and Social Media Networks. Research Report, The Open University/France Medias Monde, 13 May 2016 (2016)

GSMA: Bridging the gender gap: mobile access and usage in low and middle-income countries, 2015 (2016). http://www.gsma.com/mobilefordevelopment/wp-ontent/uploads/2016/02/ Connected-Women-Gender-Gap.pdf

Gunderson, L.H.: Ecological resilience in theory and application. Ann. Rev. Ecol. Syst. 31, 425439 (2000)

Gunderson, L.H., Holling, C.S.: Panarchy: understanding transformations in systems of humans and nature. Washington, Island (2002)

Hampton, K.N., Goulet, L.S., Albanesius, G.: Change in the social life of urban public spaces: the rise of mobile phones and women, and the decline of aloneness over 30 years. Urban Stud. 52(8), 1489-1504 (2015)

Harney, N.: Precarity, affect and problem solving with mobile phones by asylum seekers, refugees and migrants in Naples. Italy. J. Refugee Stud. 26(4), 541-557 (2013)

Holling, C.S.: Resilience and stability of ecological systems. Ann. Revi. Ecol. Syst. 4, 1-23 (1973)

Montgomery, J.: Making a city: urbanity, vitality and urban design. J. Urban Des. 3(1), 93-116 (1998)

Lindner, S., Li, L., Müller, A.: Chinese and German city policies - analysed in the cities of Chengdu, Bonn, Wuhan and Duisburg. Report, Ecofys, June 2014

Lloyd, A.: People are outraged to see refugees with smartphones. They shouldn't be. Mother Nature Network, 8 September 2015 (2015)

Lofland, L.: A World of Strangers. Prospect Heights, Waveland (1985). [1973]

Ministry of Internal Affairs of Greece: Xenocratis General Plan for Civic Protection. Ministerial Decision 1299, FEK 423 B, 10 April 2003 (2003)

Neuman, M., Smith, S.: City planning and infrastructure: once and future partners. J. Plann. Hist. 9(1), 21-42 (2010)

Orum, A.M., Neal, Z.P. (eds.): Common Ground: Readings and Reflections on Public Space. Routledge, New York (2010)

Pyrpiri, L.: Spatial planning and management of refugee flows. Undergraduate thesis, DPRD, University of Thessaly (2017)

Schmitt, P., Iland, D., Belding, E., Tomaszewski, B., Xu, Y., Maitland, C.: Community-level access divides: a refugee camp case study (2016)

Sheffield University: Refugees welcome in parks project (2017). http://thebench-project.weebly. $\mathrm{com} / \mathrm{blog} /$ research-assistant-positionrefugeewelcome-in-parks 
Talhouk, R., et al.: Syrian refugees and digital health in Lebanon: Opportunities for improving antenatal health. In: Proceedings of the 2016 CHI Conference on Human Factors in Computing Systems. pp. 331-342. ACM, May 2016

Walker, B., Holling, C.S., Carpenter, S.R., Kinzig, A.: Resilience, adaptability and transformability in social-ecological systems. Ecol. Soc. 9(2) (2004)

Walker, B., Salt, D.: Resilience thinking: sustaining ecosystems and people in a changing world. Island Press, USA (2006)

Costa, C.S., Ioannidis, K. (eds.): The Making of the Mediated Public Space: Essays on Emerging Urban Phenomena. Lusófona University Press, Lisbon (2017)

Open Access This chapter is licensed under the terms of the Creative Commons Attribution 4.0 International License (http://creativecommons.org/licenses/by/4.0/), which permits use, sharing, adaptation, distribution and reproduction in any medium or format, as long as you give appropriate credit to the original author(s) and the source, provide a link to the Creative Commons license and indicate if changes were made.

The images or other third party material in this chapter are included in the chapter's Creative Commons license, unless indicated otherwise in a credit line to the material. If material is not included in the chapter's Creative Commons license and your intended use is not permitted by statutory regulation or exceeds the permitted use, you will need to obtain permission directly from the copyright holder. 